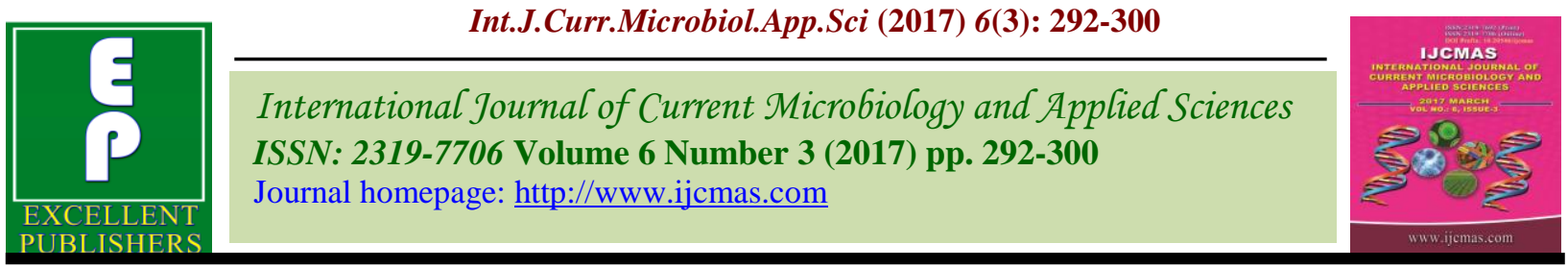

Original Research Article

https://doi.org/10.20546/ijcmas.2017.603.032

\title{
Performance Evaluation of First Flush with Micromesh Filter System under Actual Rainfall Condition
}

\author{
S.V. Lakshminarayana*, K.K. Sathian and K.V. Arjun Prakash \\ Kelappaji College of Agricultural Engineering and Technology, Tavanur, Thrissur-679573, India \\ *Corresponding author
}

A B S T R A C T

Keywords

$\mathrm{pH}, \mathrm{TSS}, \mathrm{TDS}$,

Electrical

conductivity, First

flush system.

Article Info

Accepted:

10 February 2017

Available Online:

10 March 2017
One of the easiest and efficient way of water conservation to solve drinking water scarcity is rooftop water harvesting. To evaluate the performance of the first flush with micromesh filter system, inflow and outflow of the rooftop water samples were analysed for $\mathrm{pH}, \mathrm{EC}$, TDS, SAL and TSS parameters. In general, the PH, electrical conductivity, and TDS of the roof water samples were within the drinking water standards and the first flush with micromesh filter system was found to reduce TDS values. In the case of TSS, mostly the impurities were organic in nature and concentration varied between 220 to $280 \mathrm{mg} / \mathrm{l}$, a level much higher than WHO and BIS standards. The first flush with 3 micron mesh filter is removing 100 percentage of the organic TSS impurities. The filtration rate of this filter is about $0.37 \mathrm{lps}$ at a hydraulic head of 1.5 meter and hence suites to rooftop rain water harvesting. First flush with filter system showed better cleaning efficiency when attached to the inlet side of the coarser micro mesh filters. It can be accomplished that first flush with 3 micron mesh filter system can function as a near fool proof mechanism for filtering rooftop rain water.

\section{Introduction}

Rainwater harvesting is a technology which is most eco-friendly and adaptable to a very wide variety of situations and conditions (Fayez and Al-Shareef, 2009; Constantin et al., 2010). In areas where there is variation in the seasonal rainfall pattern, the balancing of water supply and demand would be difficult. In such cases, roof water harvesting plays an important role. Rainwater falling on the roof surfaces become impure and dirty due to many substances like bird droppings, dust, dirt, leaves present on the rooftop etc. It is important that the initial rooftop runoff should be diverted away from the storage tank to avoid contamination (Dinesh, 2004; Evans et al., 2006; Dwivedi, and Bhadauria, 2004;
Farreny, 2011). Therefore, it is desirable that pure water is allowed to flow into to the storage tank after contaminants are washed away by initial rainfall for few minutes. The storage tank should be cleaned annually, otherwise some of the algae and vegetative growth can cause contamination of pure water in the storage tank, especially when water in the storage tank is stored for a long period. The storage tank should be well protected from insects breeding and high windblown places (Helmreich and Horn, 2008; Herngren et al., 2004). To maintain the quality of water, filters and separators can be used in rainwater harvesting system at the inlet. Filters separate the debris and allow the clean water flow 
through the system. The filter should not get blocked, should be easy to clean and should not allow even minor contaminants into the storage system.

\section{Materials and Methods}

\section{Study area}

Development of a First flush with micromesh filter system for roof water harvesting system and its performance, evaluation has been conducted on the first flush system with various micro mesh filter in the campus of Kelappaji College of Agricultural Engineering and Technology (KCAET), Tavanur, Malappuram Dt, Kerala, India. The Geographical reference of the study area is $75^{\circ} 59^{\prime} 5^{\prime \prime}$ E longitude and $10^{\circ} 51^{\prime} 20^{\prime \prime} \mathrm{N}$ latitude. The average annual rainfall of the study area for the last 25 years is $294 \mathrm{~cm}$. In south west monsoon (June to September), $75 \%$ of the annual rainfall is received by the area the balance $25 \%$ of rainfall is received during north east monsoon (October to November) and summer rains (December to May). Summer rains are usually very low with a typical variation of $0-5 \%$. The Climate is humid tropic with a mean annual maximum temperature of $30^{\circ} \mathrm{C}$, minimum temperature of $23.5^{\circ} \mathrm{C}$ and relative humidity $75 \%$. Major water scarcity of the region arises during the 3 summer months (March to May) due to the prolonged summer season and negligible summer showers.

\section{Design and development of first flush system}

The first flush or foul flush unit aims to divert or bypass the impurity laden rainwater collected from the rooftop. The impure water initially collected by a rainwater harvesting system is known as the "first flush" or "foul flush", and is the main source of contamination in any rooftop rainwater harvesting system. The main components of the first flush are a floating ball valve in a chamber made up of PVC pipe. The first flush system was constructed using $160 \mathrm{~mm}$ diameter PVC pipe which acts as a storage unit for the first rainfall runoff from the top of the roof temporary. The removal of initially contaminated roof water is the main focus of any first flush system. The first flush is connected to the conveyances pipes from the roof before the filtering unit, using the PVC connectors and reducers. The total capacity of the first flush system is 201 . Bottom of the first flush chamber is closed by PVC end cap. When the first runoff rainwater from the rooftop is filled up to the maximum capacity of the system, the floating valve will close the chamber from the conveyance pipe and prevent the mixing of the first runoff rainwater with the relatively more pure later coming water. The common initial contaminants in the roof top water will be dust, dirt, leaves, bird droppings, dead insects, and other particulate matter.

The sectional view of the first flush system is shown in figure 1 . The total capacity of the system has been fixed based on the volume of roof runoff water corresponding to a $1 \mathrm{~mm}$ initial rainfall. The capacity of the first flush chamber is made as 201 , so as to make it suitable for $20 \mathrm{~m}^{2}$ roof catchment, which is suitable from the point of any domestic roof water harvesting system in Kerala. A small dripper hole is provide at the bottom of the first flush system so that the chamber becomes empty before the next incoming runoff rainfall. The system help to reduce the impurities going to interact with the mesh filter.

\section{Development of upward flow micro mesh filter system and mesh filters}

The study includes the development of $60 \mu$, $40 \mu, 25 \mu, 15 \mu, 12 \mu, 7 \mu, 5 \mu$ and $3 \mu$ mesh filters. In all cases the micro meshes used were made of stainless steel of grade 316 . To make the filter element, $50 \mathrm{~mm}$ PVC pipe of 
$30 \mathrm{~cm}$ length is taken and slots of $5 \mathrm{~mm} \phi$ were made on it at an approximate spacing of $15 \mathrm{~mm}$ centre to centre in the case of all filters except for 40 micron mesh filter. Number of holes in these filters varies from 196 to 230 . Mesh area and slot area of different filter elements are shown in table 1.

\section{Performance evaluation of the first flush system}

Mainly the first flush system for roof water harvesting is provided to collect and divert the highly contaminated water flowing down from the roof during the initial few minutes of starting of rainfall events. It is designed to check the mixing of first coming highly impure roof water with the next coming relatively cleaner roof water. Evaluation of the first flush system was carried out in two different modes: by not connecting with the filter and by connecting with the filter. As conducting the experiment under actual rainfall condition was very difficult as has been explained in the evaluation of mesh filters, simulated rainfall was created in this case also. Performance of the first flush unit was performed by connecting the unit before the mesh filter of the roof water harvesting arrangement. After the first flush, all the eight different mesh filters were tested in series, one at a time with the first flush system is shown in figure 2 Samples for water quality testing were collected from the inlet of the first flush and from the outlet end of the mesh filter. The experiment was repeated for each mesh filter cum first flush combination. All the water quality parameters tested in the case of 'filter alone' case has also been done for filter cum first flush combination.

\section{Working of first flush with filter system under actual rainfall}

Rainwater coming down from the rooftop through the gutter and downpipe is conveyed to the first flushing unit having 201 capacity.
This first flush tank collect 201 of initially generated most contaminated water. As the water level rises in the first flush chamber, the ball floats on the water surface and once the chamber is full, the ball presses upward against the inlet to the flush chamber and closes it, and thereby preventing any further entry of roof water into it. The subsequent flow of water is then automatically directed to the upward flow filter system along a $90 \mathrm{~mm}$ pipe where the incoming flow velocity is reduced and the debris is allowed to settle. Then, the rainwater with reduced velocity of flow move upward through the annular space between the casing pipe and the filter element. Water then passes through the micro mesh of the filter where removal of suspended particles takes place. The filtered water then moves to the storage tank. The entire movement of water from the roof to the storage tank takes place under gravity force without the use of any additional energy.

Impure water collected in the first flush chamber will be drained slowly by dripping water through the dripper hole of $2 \mathrm{l} / \mathrm{h}$ discharge rate. It may take about 10 hours for emptying the chamber. Thus, the first flush chamber will be ready to receive and store the next lot of initial incoming roof water. The chamber can be cleaned by opening the end cap at the bottom. As the micro mesh filter unit is designed for the pass of water in upward direction, major portion of the suspended particles is settled at the bottom of the casing pipe and will reduce the load of impurities reaching the mesh filter. Impurities settled at the bottom can be removed by opening the end cap provided at the bottom and flushing.

\section{Estimation of water quality parameters}

A water quality analyzer, Systronics Water Quality Analyser 371 was used to carry out the physical analysis of the collected rooftop rain water samples. It is a micro controller 
based instrument for measuring $\mathrm{pH}$, salinity, electrical conductivity and TDS in water sample one at a time. The analyser provides both automatic and manual temperature compensation. Calibration or standardization of the instrument was done with standard solutions. The important physical parameters which include $\mathrm{pH}$, electrical conductivity, salinity and TDS of the rainwater and roof water samples collected for the study were tested with water quality analyser. Procedure adapted for testing each quality parameter of roof water samples collected for analysis is presented below.

\section{pH}

The acidity or alkalinity of water is expressed as $\mathrm{pH}$. The $\mathrm{pH}$ of an aqueous solution is a measure of the acid base equilibrium achieved by various dissolved compounds. The Bureau of Indian Standards (BIS) recommendation of $\mathrm{pH}$ for drinking water is 6.5 to 8.5 . Water quality analyzer determines the $\mathrm{pH}$ using $\mathrm{pH}$ electrode. The $\mathrm{pH}$ meter measures the potential difference and its changes across the glass membrane. The potential difference must be obtained between two points; one is the electrode contacting with the internal solution and the second point is obtained by connecting to a reference electrode, immersed in the solution under study.

\section{Electrical conductivity}

The electrical conductivity of the water also depends on the water temperature. While the electrical conductivity is a good indicator of the total salinity, it still does not provide any information about the ion composition in the water. Many EC meters nowadays automatically standardize the readings to $250^{\circ} \mathrm{C}$. The commonly used units for measuring electrical conductivity of water are $\mu \mathrm{S} / \mathrm{cm}$ (microSiemens $/ \mathrm{cm}$ ) or $\mathrm{dS} / \mathrm{m}$ (deciSiemens/m). In the case of conductivity of the drinking water, the acceptable limit is up to $1500 \mu \mathrm{S} / \mathrm{cm}$, according to BIS standards.

\section{Salinity}

Salinity means the amount of dissolved salts present in the water. Salt compounds like magnesium sulphate, sodium chloride, sodium bicarbonate and potassium nitrate. It is commonly measured in parts per thousand (ppt). Salinity effects animals living in water, aquatic plants and affects water quality as a whole. The rainwater samples normally will have low salinity value. However, harvested rooftop water can have different level of salinity due to the interaction of rainwater with the roof surface.

\section{Total dissolved solids}

The total dissolved solids concentration is the sum of the cations (positively charged) and anions (negatively charged) ions in the water. Therefore, the total dissolved solids test is a qualitative measure of the amount of dissolved ions. TDS test does not tell the nature or ion relationships. Since the relationship is not constant, total dissolved solids concentration can be related to the conductivity of the water. The relationship between total dissolved solids and conductivity is a function of the type and nature of the dissolved cat ions and anions in water.

\section{Total suspended solids by gravimetric method}

For measuring suspended solids, the water is filtered through a fine filter (Whattmann, Grade 1, $110 \mathrm{~mm} \phi$ ) and the dried and cooled material retained on the filter is weighed. The drying was carried out for one hour in an oven at $105^{\circ} \mathrm{C}$. The filter paper was dried prior to the filtration for 30 minutes in order to make 
the water content of the filter paper equal to that after drying with filtered out impurities. Hence, the filter paper with impurities dried in the oven is kept in the room temperature for about 30 minutes for cooling and then only its weight is determined

Total suspended solids in $\mathrm{g} / \mathrm{l}=\frac{W_{2}-W_{1}}{V} \times 1000$

Where,

$\mathrm{W}_{1}=$ Initial weight of filter paper, $\mathrm{g}$

$\mathrm{W}_{2}=$ Weight of filter paper and the dry material retained on the filter, $g$

$\mathrm{V}=$ Volume of water sample, $\mathrm{ml}$

\section{Results and Discussion}

Performance evaluation of the first flush systems has also been done under actual rainfall condition. It is connected at the inlet side of the upward flow filter system. The total experimental system adopted for the evaluation of the filter system was also done in the case of first flush system. Rooftop rain water samples were analysed for the water quality parameters of $\mathrm{pH}, \mathrm{EC}, \mathrm{SAL}, \mathrm{TDS}$ and TSS by repeating the experiment by connecting the first flush in series with the filter system, with the first flush in the inlet end of the micromesh filter.
Performance evaluation of First flush with different micromesh filters

\section{pH}

The $\mathrm{pH}$ of the roof water samples collected from the inlet and outlet end of the first flush cum filter system are given in figure 3 . No markable changes were seen in the $\mathrm{pH}$ the roof water inflow and outflow samples when compared to that of the "only mesh filter" case.

\section{Electrical conductivity (EC)}

The electrical conductivity (EC) values of the inflow and outflow roof water samples with the first flush cum filter system are presented in figure 4 . The results were not appreciably different from that of filter alone case. Hence, it is to be inferred that the addition of first flush is not making any markable positive impact on the water quality parameter, EC of roof water.

\section{Total dissolved solids (TDS)}

The TDS valves of inflow and outflow roof water samples are presented in figure 5. In this case also, the results were not appreciably different from that of "filter only" case.

Table.1 Mesh area and slot area of different filter elements

\begin{tabular}{|c|c|c|c|}
\hline Mesh size $(\boldsymbol{\mu})$ & Mesh area $\left(\mathbf{c m}^{2}\right)$ & No. slots & Slot area $\left(\mathbf{c m}^{2}\right)$ \\
\hline 60 & 447.45 & 229 & 44.96 \\
\hline 40 & 447.45 & 124 & 24.35 \\
\hline 25 & 447.45 & 196 & 38.48 \\
\hline 15 & 447.45 & 230 & 45.16 \\
\hline 12 & 447.45 & 230 & 45.16 \\
\hline 7 & 447.45 & 230 & 45.16 \\
\hline 5 & 447.45 & 230 & 45.16 \\
\hline 3 & 447.45 & 230 & 45.16 \\
\hline
\end{tabular}


Fig.1 Sectional view of the first flush system

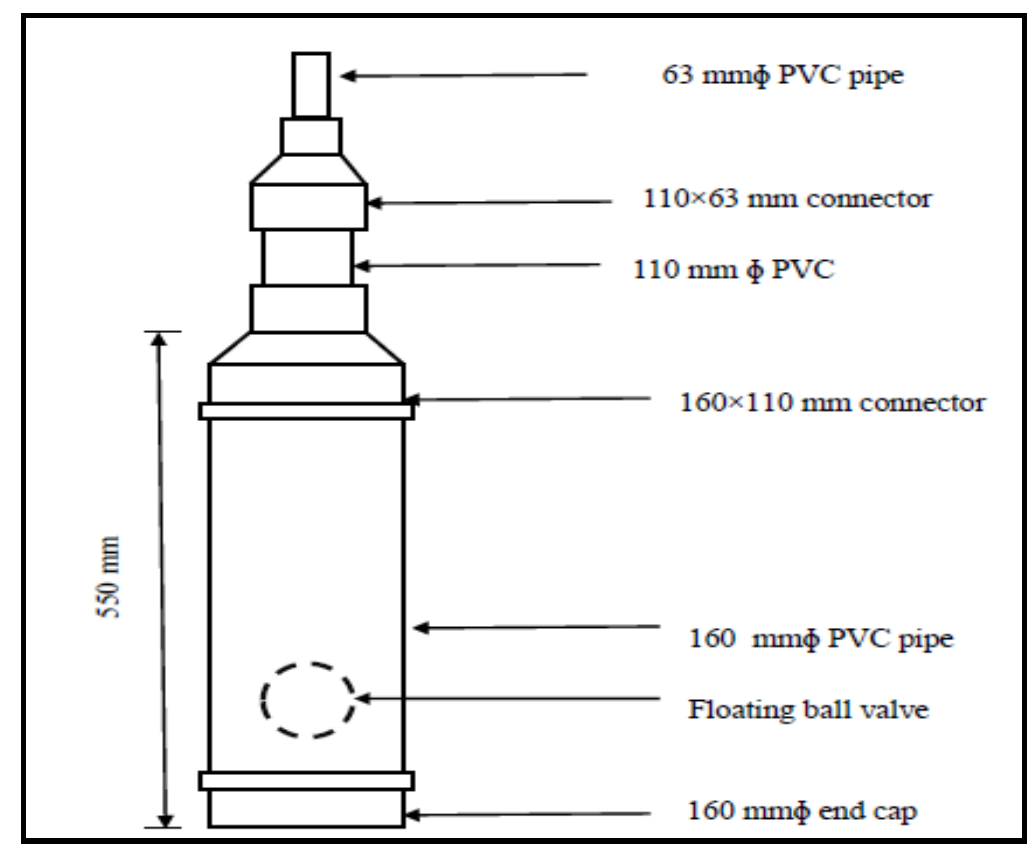

Fig.2 Complete sectional view of the first flush and mesh filter system

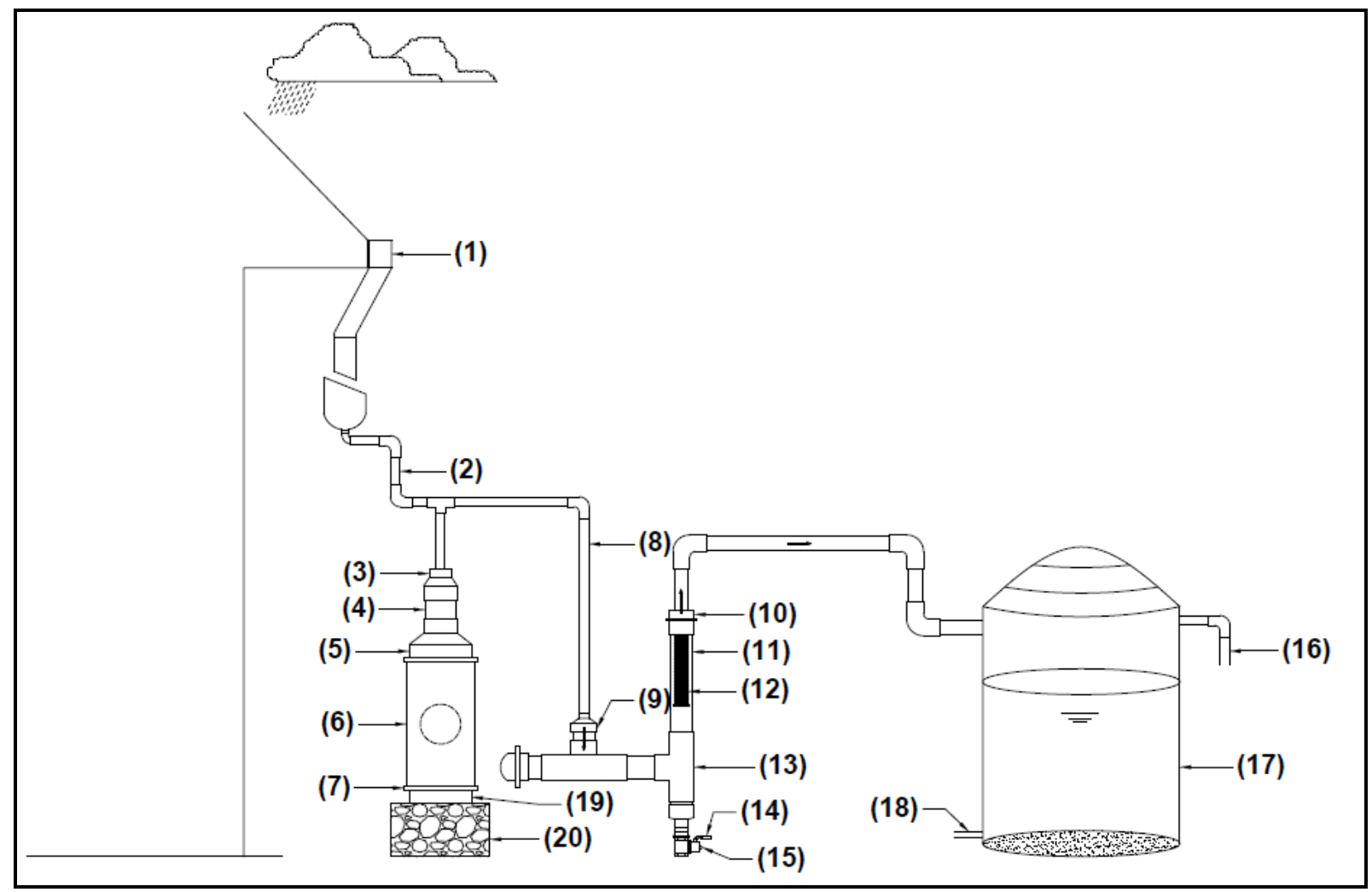


Fig.3 pH of roof water samples for first flush with filter system

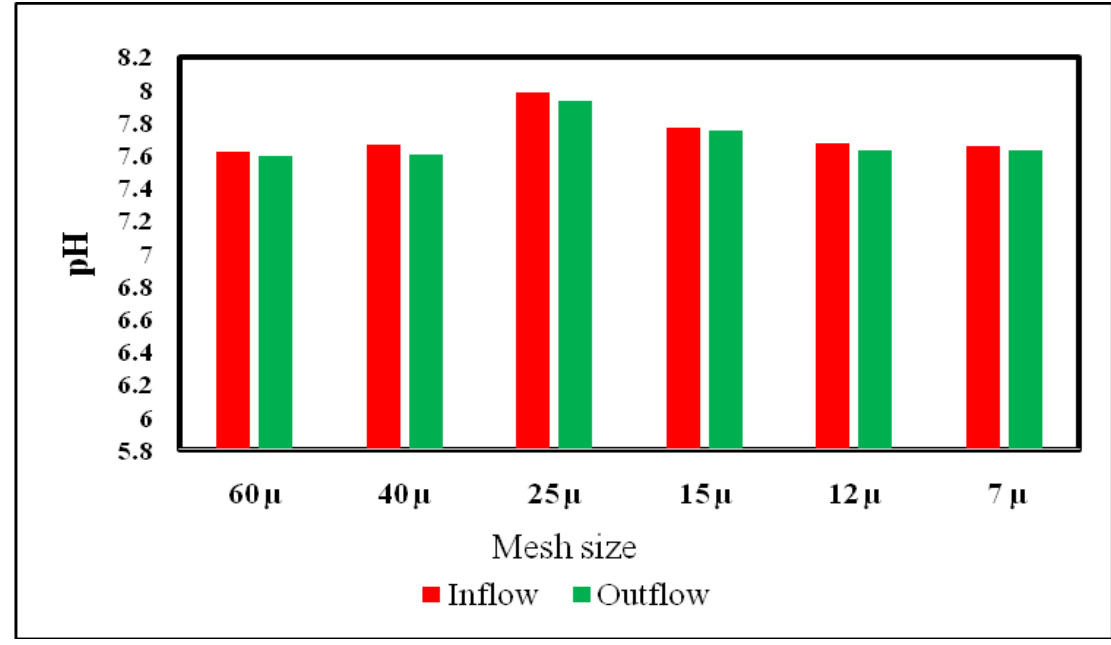

Fig.4 EC of roof water samples for first flush with filter system

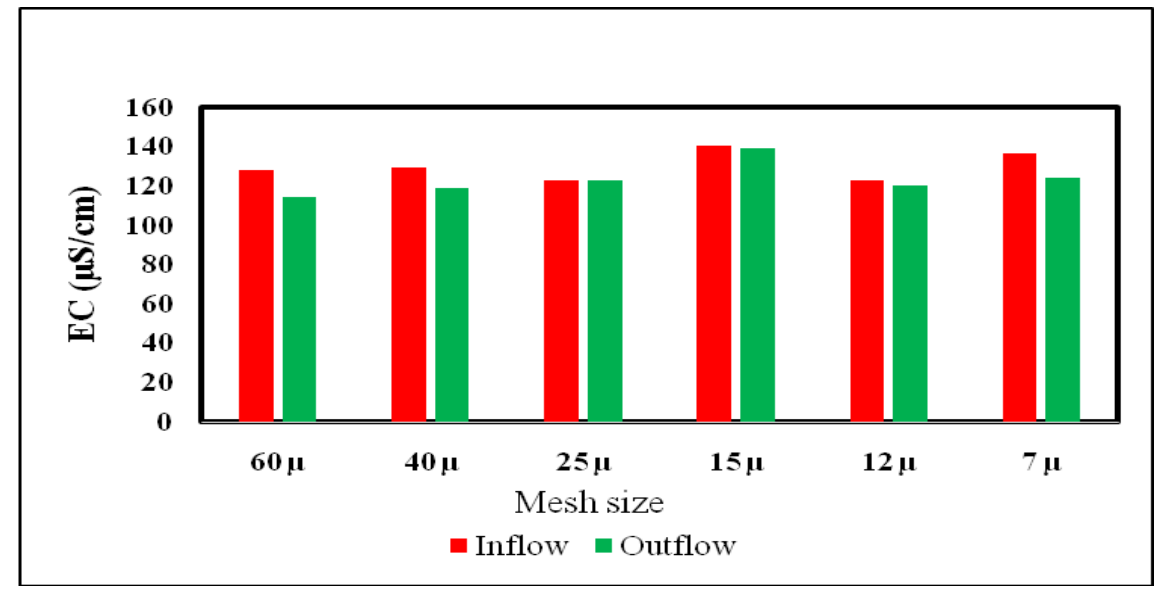

Fig.5 TDS of roof water samples for first flush with filter system

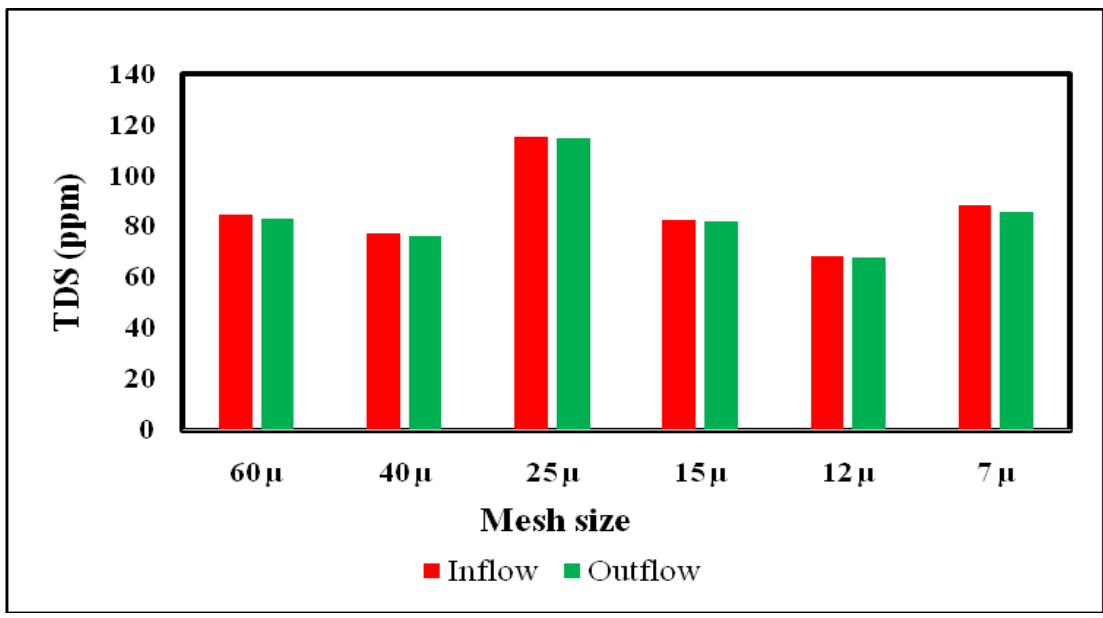


Fig.6 Salinity of roof water samples for first flush with filter system

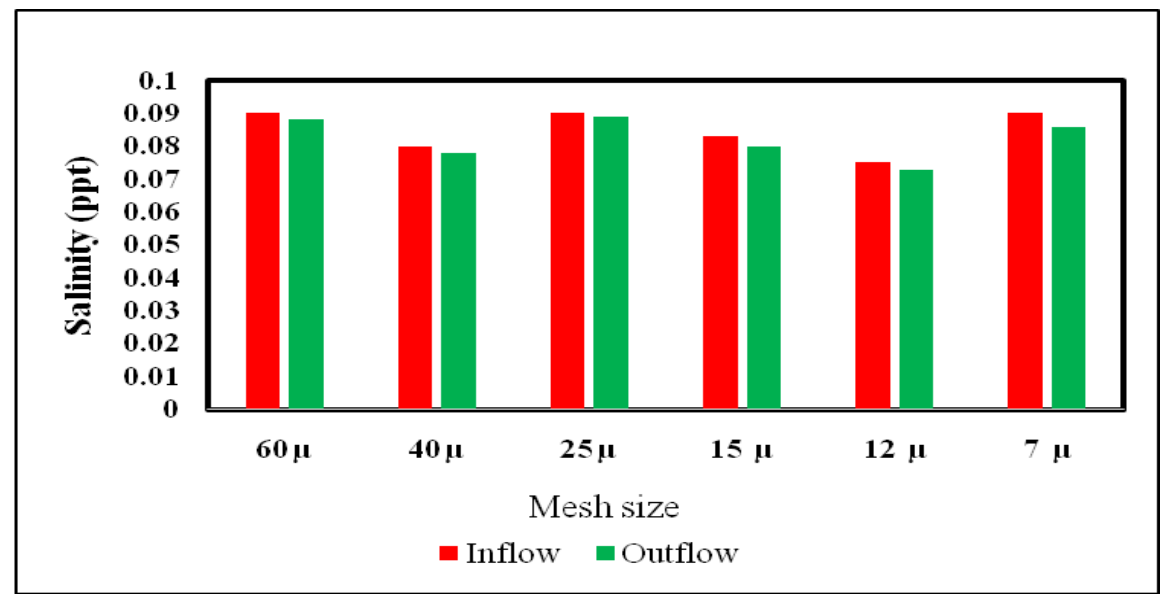

Fig.7 TSS of roof water samples for first flush with filter system

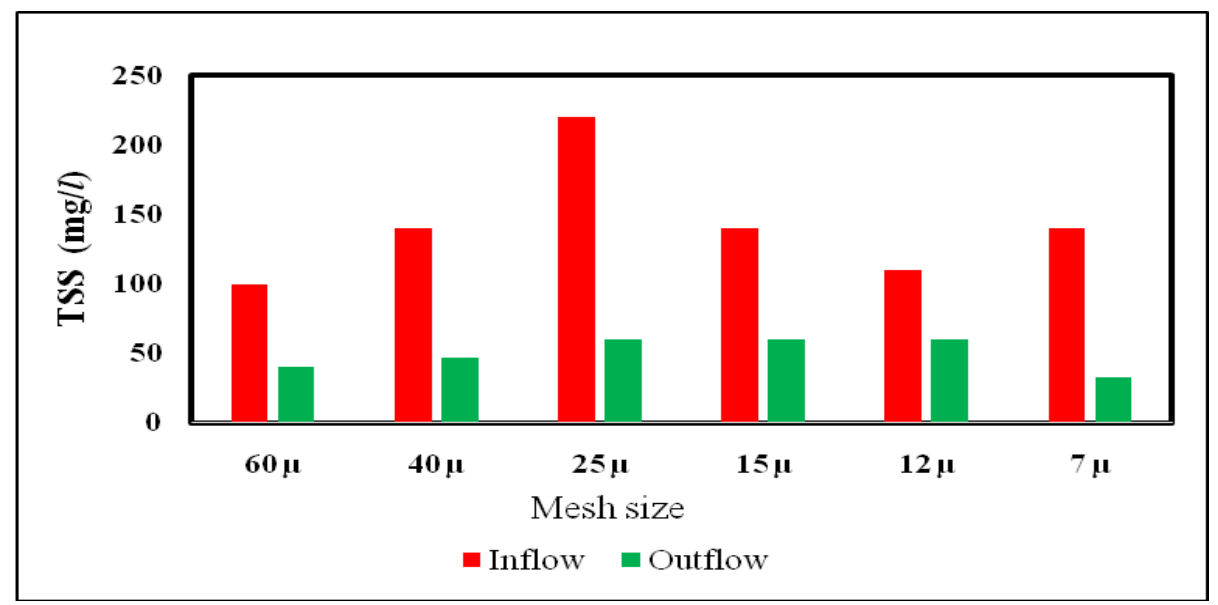

\section{Salinity (SAL)}

The salinity values of the inflow and outflow roof water samples are presented in figure 6 . The results were not considerably different from that of filter alone case. Hence, it is to be inferred that the addition of first flush is not making any markable reduction of the water quality parameter, salinity of roof water.

\section{Total suspended solids (TSS)}

The results of the analysis of the TSS of the inflow and outflow samples of the first flush and filter combination is given in figure 7.
There is considerable reduction in the TSS of outflow samples compared to the "only filter" case. The reduction is about 30 percentage in the case of coarser micron mesh filters viz. 60, 40 and 25 micron. This reduction of TSS can be attributed to the positive contribution of the first flush system.

In conclusion, the first flush system was able to collect 201 of initial most impure water generated and was capable of diverting it from the filter system and thereby reducing the impurities load on it. Impure water collected in the first flush tank was not getting mixed with the relatively cleaner roof water passing through after the initial period. Use of 
first flush in combination with mesh filters showed beneficial results in removing the suspended impurities (about 20 percentage decrease) in the case of 60,40 and $25 \mu$ mesh filters. First flush significantly reduces the impurities load in inflow water going to the micro mesh filter. It can be concluded that 3 micron mesh filter with automatic flush can function as a fool proof mechanism for filtering rooftop rain water.

\section{References}

Constantin, N., Sorin, C., Roxana, D.B., Floarea, B., and Gheorghe, S. 2010. System of Rainwater Collection, Storage and Pumping. J. Food. Agric. Environ., 8(3 and 4): 1332-1334.

Dinesh, K.M. 2004. Roof water harvesting for domestic water security: who gains and who loses. International Water Management Institute, Gujarat, India. Water Int., (29): 43-53.

Dwivedi, A.K. and Bhadauria S.B. 2004. Domestic rooftop water harvesting. $J$. Eng. Appl. Sci., 4: 31-38.
Evans, C.A., Coombes, P.J., and Dunstan, R.H. 2006. Wind, rain and bacteria: The effect of weather on the microbial composition of roof-harvested rainwater. J. Water Res., 40: 37-44.

Fayez, A.A. and Al-Shareef, A.W. 2009. Roof rainwater harvesting systems for household water supply in Jordan. Desalination, 243: 195-207.

Farreny, R., Morales-Pinzo, T., Guisasola, A., Taya, C., Rieradevall, J., Gabarrell, X. 2011. Roof selection for rainwater harvesting: Quantity and quality assessments in Spain. Water Res., 45: 3245-3254.

Helmreich, B. and Horn, H. 2008. Opportunities in rainwater harvesting. IWQC, Germany. pp. 118-124.

Herngren, L., Ashantha, G., and Godwin, A. 2004. Investigation of urban water quality using artificial rainfall, 24-25.

Jain, R.K., Singh, H., Amar, V., Sagar, B., and Deepak, S. 2015. Study of Water Distillation by Solar Energy in India. Int. J. Mech. Eng. Inf. Technol., 10041009.

\section{How to cite this article:}

Lakshminarayana, S.V., K.K. Sathian and Arjun Prakash, K.V. 2017. Performance Evaluation of First Flush with Micromesh Filter System under Actual Rainfall Condition. Int.J.Curr.Microbiol.App.Sci. 6(3): 292-300. doi: https://doi.org/10.20546/ijcmas.2017.603.032 